\title{
Cryopreservation of Dendrobium cruentum Rchb. f. Seeds by D Cryo-plate and V Cryo-plate Techniques
}

\author{
Sasikarn PRASONGSOM ${ }^{1}$, Kanchit THAMMASIRI ${ }^{2, *}$, \\ Jarunya NARANGAJAVANA ${ }^{1}$, Siripong THITAMADEE ${ }^{1}$, \\ Ngarmnij CHUENBOONNGARM ${ }^{2}$ and Nathinee PANVISAVAS ${ }^{2}$ \\ ${ }^{I}$ Department of Biotechnology, Faculty of Science, Mahidol University, Bangkok 10400, Thailand \\ ${ }^{2}$ Department of Plant Science, Faculty of Science, Mahidol University, Bangkok 10400, Thailand
}

("Corresponding author's e-mail: kanchitthammasiri@gmail.com)

Received: 26 October 2018, Revised: 23 February 2019, Accepted: 18 March 2019

\begin{abstract}
Dendrobium cruentum Rchb. f. is a native Thai orchid species that has faced extinction because of its attractive characteristics. Consequently, conservation of this species is urgently needed. In this study, cryopreservation technique was applied to D. cruentum Rchb. f. seeds for long-term conservation. A successful protocol for D. cruentum Rchb. f. seed cryopreservation was developed by using D cryoplate and V cryo-plate techniques. Seed viability was tested by TCC solution and $93.8 \%$ of dyed seeds were shown. For cryo-plate technique, seeds were encapsulated over the cryo-plate by using $2 \%(\mathrm{w} / \mathrm{v})$ sodium alginate and polymerized with $100 \mathrm{mM} \mathrm{CaCl}_{2}$. Encapsulated seeds were desiccated by using a laminar airflow and PVS2 solution treatment with the same exposure time (0, 30, 60, 90, and $120 \mathrm{~min})$. After cryopreservation, encapsulated seeds were cultured on modified VW agar medium. From the results, the maximum germination and regrowth percentage were observed; D cryo-plate technique with $60 \mathrm{~min}$ of dehydration time gave the highest germination $(68.9 \%)$ and regrowth $(57.8 \%)$. Thus, the excess of dehydration may cause the reduction of germination and plant regeneration. In conclusion, D cryo-plate technique proved to be appropriate for $D$. cruentum Rchb. f. seed cryopreservation.
\end{abstract}

Keywords: Orchid, Dendrobium cruentum Rchb. f. seeds, cryopreservation, D cryo-plate, V cryo-plate

\section{Introduction}

Cryopreservation has been proven to be an effective technique for preservation of organisms and biological tissues and is intensively used to conserve various plant species [1]. In addition, this technique is currently available, ensuring the safe, efficient, and cost-effective long-term storage of plant germplasm [2]. The use of ultra-low temperatures (liquid nitrogen, temperature below -150 to $-196^{\circ} \mathrm{C}$ ) stops metabolic and biochemical processes, such as cell division and growth in cells, tissues and organs $[3,4]$. However, the limitation of cryopreservation is the damage to living cells (suspended cells, tissues, or organs) by intracellular ice formation during the cooling and rewarming steps [5].

Different techniques have been described during the development of cryopreservation processes, from classic technique (slow freezing), contemporary technique (vitrification, encapsulation-dehydration and encapsulation-vitrification) and, recently, new technique (cryo-plate) [6-12]. Slow freezing is composed of two phases, I: slow reduction of temperature $\left(1\right.$ to $\left.10^{\circ} \mathrm{C} \mathrm{min}^{-1}\right)$ and II: rapidly through direct immersion of the materials in LN [13]. However, slow freezing has a limitation of freeze injury due to the formation of intracellular ice in plant materials [14]. Vitrification, encapsulation-vitrification, and encapsulation-dehydration are representatives of contemporary techniques [15]. These techniques are based on the dehydration of materials before freezing to avoid the formation of ice crystals by using 
http://wjst.wu.ac.th

osmotic dehydration (cryoprotectant solution) or desiccation method (a laminar airflow cabinet or silica gel) before rapid freezing [16]. Therefore, appropriate and compatible water content in materials have to be balanced to lead to high survival rates. Vitrification has been successfully used for plant cell cryopreservation since 1990 [17]. For the vitrification process, plant materials are treated with concentrated cryoprotectant solution (PVS2), including dimethyl sulfoxide, ethylene glycol, glycerol, propylene glycol, and sucrose [18]. The combination of vitrification and encapsulated beads (calcium alginate beads) were proposed as an encapsulation-vitrification technique. However, encapsulationdehydration has been described by Fabre and Dereuddre [19] by combining the encapsulated beads with the desiccation process to remove water from plant material before immersion into liquid nitrogen. This technique was accomplished in shoot tips of Dendrobium Walter Oumae [20]. Dehydration process is based on the successive osmotic and evaporative dehydration of plant cells, prior to the cooling step (LN). Dehydration techniques by sterile airflow allow more flexibility when handling large samples because the process is less time-critical and toxic than vitrification technique [15]. Moreover, a new technique has been developed known as the cryo-plate technique [11]. Cryo-plate is an aluminum plate that has high heat transfer property for cooling $\left(4,000-5,000{ }^{\circ} \mathrm{C} \min ^{-1}\right)$ and rewarming $\left(3,000-4,500{ }^{\circ} \mathrm{C} \min ^{-1}\right)$ rates, which protects explants from freezing damage by ice nucleation [11, 12]. Yamamoto [11] first reported using cryo-plate as a V cryo-plate technique, which is the combination of cryo-plate and plant vitrification solution 2 (PVS2) treatments. After that, Niino [12] proposed the developed technique (D cryo-plate) to avoid cryoprotectant toxicity and physical damage by changing the dehydration method from PVS2 solution to sterile laminar airflow dehydration [21]. A successful cryopreservation protocol for different plant materials and species by using cryo-plate techniques were reported, including carnation [22], strawberry [23], mint [24], potato [25], mat rush [21], Perilla frutescens [26], date palm [27], Clinopodium odorum [28], Cleome rosea Vahl [29], sugarcane [30], and Ullucus tuberosus Cal. [31].

Orchidaceae is one of the largest and most diverse families of flowering plants in the world [32]. Genus Dendrobium comprises 1,184 species [33] and more than 150 native species are found in Thailand [34]. Dendrobium species became popular because of the economic value of different hybrids that are used as cut-flower and potted plants [35]. In contrast, most native Dendrobium species are critically decreased in the natural ecosystem because of over-collection and deforestation. Dendrobium cruentum Rchb. f. is one of the endemic species that originated in southwestern or peninsular Thailand. Their habitat is in open forests at low elevations on small trees. Characteristics of D. cruentum Rchb. f. are 20 $30 \mathrm{~cm}$ stem length, sepals and petals pale green with dark green veins, lips creamy white flushed with brilliant red, and flowering around the year, and with suitable culture conditions of $27-30{ }^{\circ} \mathrm{C}$ day and 21 - $22{ }^{\circ} \mathrm{C}$ night and relative humidity around $80-85 \%(\mathrm{RH})$ [36]. D. cruentum Rchb. f. has commercial value because it produces many outstanding hybrids, such as Dawn Maree (Dendrobium cruentum $\mathrm{x}$ Dendrobium formosum), Green Lantern hybrid, and Frosty Dawn hybrid. Due to the ecological aspects, D. cruentum Rchb. f. is facing extinction. Since 2004, this species has been listed in the IUCN CITES Appendix (I) as a 'World Endangered Orchid Species". Therefore, conservation of D. cruentum Rchb. f. is urgently needed. There have been a few reports on D. cruentum Rchb. f. seeds and protocorms cryopreservation by using vitrification and encapsulation-dehydration techniques [37,38]. However, only a 20 to $30 \%$ survival rate was reached by previous reports. In this study, we aim to optimize the suitable dehydration time and technique for $D$. cruentum Rchb. f. seeds cryopreservation by using D cryo-plate and V cryo-plate techniques.

\section{Materials and methods}

\section{Plant materials}

Fresh 4-month-old capsules of D. cruentum Rchb. f. were taken from the saranhouse of the Department of Plant Science, Faculty of Science, Mahidol University, Salaya campus, Thailand (Figure 1B). 
http://wjst.wu.ac.th

\section{Seed quality test}

fresh seed viability was assessed using a $1 \%$ of 2, 3, 5-triphenyl tetrazolium chloride (TTC) solution. Seeds were added to $20 \mathrm{~mL}$ of TTC solution in a screw cap tube and kept in the dark at $30{ }^{\circ} \mathrm{C}$ for $24 \mathrm{~h}$. Thereafter, the orange-red stained viable seeds and yellowish unstained seeds were counted under a light microscope.

\section{Determination of moisture content (MC)}

$2 \%(\mathrm{w} / \mathrm{v}) \mathrm{Na}$-alginate prepared in VW medium was poured in each well of the cryo-plate. After that, 20 - 50 seeds were placed in each well. The mixture was dispended into $0.1 \mathrm{M} \mathrm{CaCl}_{2}$ solution for 20 min at $25 \pm 2{ }^{\circ} \mathrm{C}$ for bead forming. Encapsulated seeds of D. cruentum Rchb. f. were placed in glass petri dishes and dried in a sterile laminar airflow cabinet at room temperature $\left(25 \pm 2{ }^{\circ} \mathrm{C}\right)$ for various times $(0$, $30,60,90,120,180,240,300$, and $360 \mathrm{~min})$ to reduce moisture content. Fresh weights of encapsulated seeds were immediately recorded for different dehydration times. After that, samples were dried in a hot air oven at $130{ }^{\circ} \mathrm{C}$ for $24 \mathrm{~h}$ until each sample reached a constant dry weight. The moisture content was calculated by using the following wet basis equation;

$\mathrm{MC}_{\mathrm{wb}}=\frac{W i-W f}{W f} X 100$

where; $\mathrm{MC}_{\mathrm{wb}}=$ Moisture content basis $(\%) ; \mathrm{W}_{\mathrm{i}}=$ Initial weight (gram); $\mathrm{W}_{\mathrm{f}}=$ Final weight $($ gram)

\section{Dehydration cryo-plate technique (D cryo-plate)}

$2 \%(\mathrm{w} / \mathrm{v}) \mathrm{Na}$-alginate prepared in VW medium was poured in each well of the cryo-plate. After that, 20 - 50 seeds were placed in each well. The mixture was dispended into $0.1 \mathrm{M} \mathrm{CaCl}_{2}$ solution for 20 $\min$ at $25 \pm 2{ }^{\circ} \mathrm{C}$ for bead forming. Then, the cryo-plates were exposed to loading solution ( $2 \mathrm{M}$ glycerol and $0.4 \mathrm{M}$ sucrose) at room temperature for $20 \mathrm{~min}$. After that, samples were dehydrated by subjecting them to a laminar airflow cabinet at $25 \pm 2{ }^{\circ} \mathrm{C}$ for $0,30,60,90$, and 120 min. Cryo-plates were transferred to uncapped $2 \mathrm{ml}$ plastic cryotubes held on a cryo-cane, and directly plunged in LN for at least $1 \mathrm{~h}$. After that, cryo-plates were removed from $\mathrm{LN}$ and placed into un-loading solution (1.2 M sucrose) for $15 \mathrm{~min}$. Cryopreserved seeds were cultured on modified VW agar medium. For control treatment, D cryo-plate was loaded and dehydrated in a laminar airflow cabinet, as described above, and cultured on modified VW agar medium.

\section{Vitrification cryo-plate technique (V cryo-plate)}

$2 \%(\mathrm{w} / \mathrm{v}) \mathrm{Na}$-alginate prepared in $\mathrm{VW}$ medium was poured in each well of the cryo-plate. After that, 20 - 50 seeds were placed in each well. The mixture was dispended into $0.1 \mathrm{M} \mathrm{CaCl}_{2}$ solution for 20 $\min$ at $25 \pm 2{ }^{\circ} \mathrm{C}$ for bead forming. Then, the cryo-plates were exposed to loading solution ( $2 \mathrm{M}$ glycerol and $0.4 \mathrm{M}$ sucrose) at room temperature for $20 \mathrm{~min}$. For V cryo-plate, it was dehydrated by PVS2 solution at $25 \pm 2{ }^{\circ} \mathrm{C}$ for $0,30,60,90$, and 120 min. Cryo-plates were transferred to uncapped $2 \mathrm{ml}$ plastic cryotubes held on a cryo-cane, and directly plunged in LN for at least $1 \mathrm{~h}$. After that, cryo-plates were removed from LN and placed into un-loading solution (1.2 M sucrose) for $15 \mathrm{~min}$. Cryopreserved seeds were cultured on modified VW agar medium. For control treatment, V cryo-plate was loaded and dehydrated with PVS2 solution, as described above, and then cultured on modified VW agar medium.

\section{Germination and regrowth evaluation}

After cryopreservation, seeds were cultured on modified VW agar medium under a $16 \mathrm{~h}$ photoperiod at $25 \pm 2{ }^{\circ} \mathrm{C}$. Germination percentage was assessed for 4 weeks by recording the number of imbibed viable embryos and spherical protocorm formation. Seedling formation was assessed as a regrowth after 12 weeks of culture. 
http://wjst.wu.ac.th

\section{Statistical analysis}

Changes in mean moisture content of encapsulated seeds $(n=10)$ during the dehydration process by sterile laminar airflow were subjected to a $\mathrm{T}$-Test $(\mathrm{P} \leq 0.05)$. For the cryopreservation experiments, germination and regrowth of cryopreserved seeds are presented as mean values $( \pm \mathrm{SE})$. Experiments were repeated three times of ten encapsulated beads per treatment. Statistical analysis was performed using ANOVA at $\mathrm{P} \leq 0.05$, and the means were compared using completely randomized design (CRD) by the Duncan's New Multiple Range Test (SPSS Statistic 21 software).

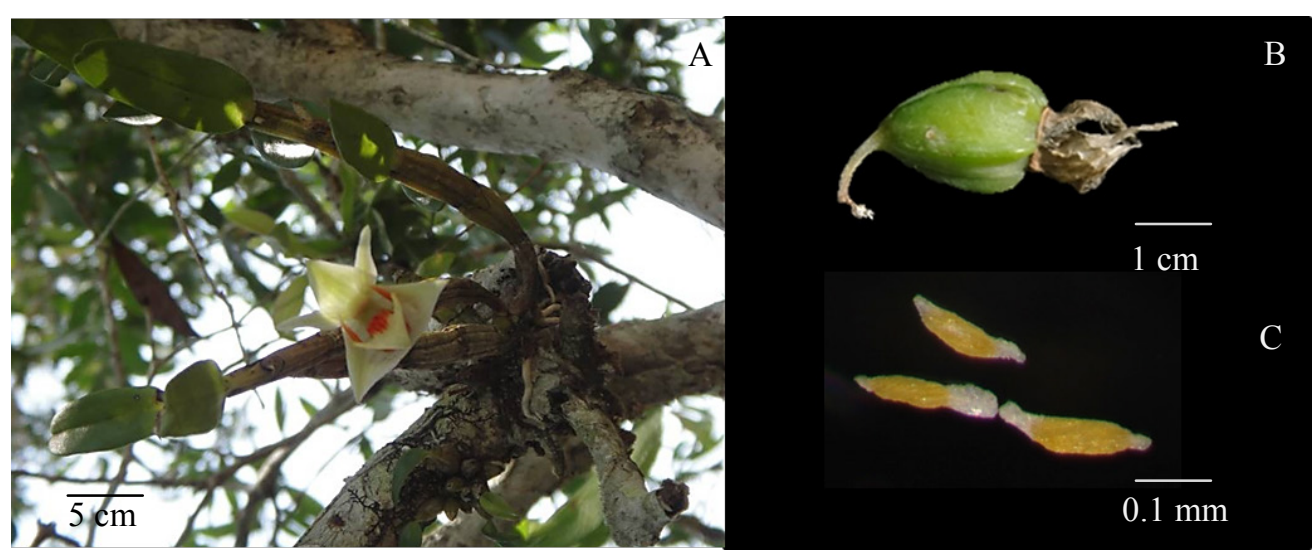

Figure 1 Plant, capsule and seed characteristics of Dendrobium cruentum Rchb. f. A) Plant in natural habitat, B) Mature capsule and C) seeds. Scale bar $=5 \mathrm{~cm}(\mathrm{~A}), 1 \mathrm{~cm}(\mathrm{~B})$ and $0.1 \mathrm{~mm}(\mathrm{C})$.

\section{Results and discussion}

\section{Seed quality}

The seed viability test by TTC staining method showed $93.8 \%$ orange-red stained embryo (Figure 2A). Seeds without stained and empty (embryoless) seeds (Figure 2B; No. 1 and 2) were excluded from the germination assessment, and only the response of full seeds (Figure 2A) was considered. The different seed lots had to be tested for quality before use. Singh [39] reported the successful use of TTC on tropical epiphyte seed quality test. However, the prior test by TTC can indicate rough assessment to seed germination possibility before long-term cryopreservation [40].

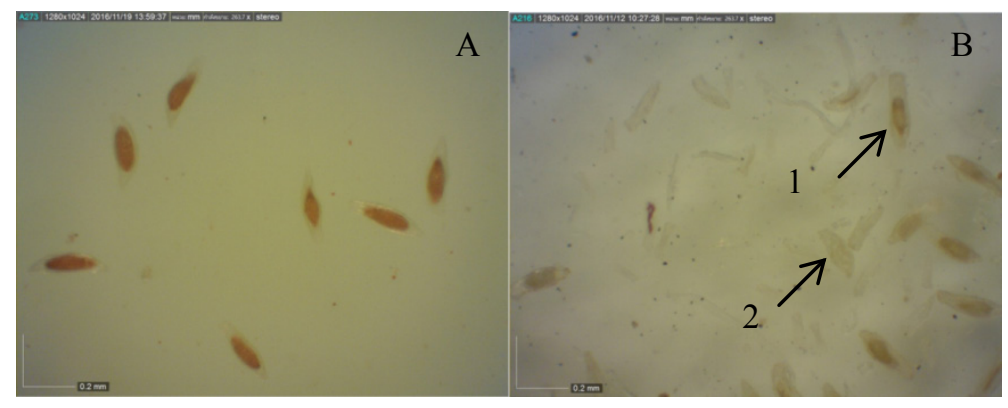

Figure 2 TTC seed viability test for Dendrobium cuentum Rchb. f. A) Viable seeds with orange-red stained embryos, B) Non-viable seeds without orange-red stained embryos (1) and embryoless seeds (2). Scale bar $=0.2 \mathrm{~mm}$. 
http://wjst.wu.ac.th

\section{Determination of moisture content (MC)}

From the results, the calculation of moisture content by wet basis equation is shown in Figure 3 with 30 and $60 \mathrm{~min}$ intervals. Interestingly, only $30 \mathrm{~min}$ after dehydration by $\mathrm{D}$ cryo-plate technique showed dramatically reduction from 96.7 to $36.6 \%$. At 60 min of dehydration, D cryo-plate technique decreased the moisture content to $13.5 \%$. After 90 to $360 \mathrm{~min}$, constant moisture content of around 2 to 3 $\%$ was recorded. The results indicated that the suitable time for dehydration of D cryo-plate is around 30 $60 \min (36.56,12.54 \%$ moisture content). Volk and Walters [41] reported that moisture contents of less than $0.25-0.40 \mathrm{~g} \mathrm{H}_{2} \mathrm{O} \mathrm{g} \mathrm{dm}{ }^{-1}(20-28.57 \%$ moisture content of wet basis) were often referred to as 'unfreezable', which results in low cell water content without causing cell death [42]. Determination of moisture content played an important role in indicating the appropriate dehydration time for plant materials to reduce remaining water before cryopreservation. The remaining water in plant material is the main factor that causes the cellular ice formation, which causes cell lethality, injury, and leakage of intracellular components out of the cells [24]. Many reports indicated that the optimum moisture content of encapsulated seeds was species specific [16,43-45]. In the case of Vanda coerulea, high regrowth rate of cryopreserved protocorms was observed after $8 \mathrm{~h}$ of dehydration and reached $35 \%$ of moisture content [46]. Therefore, the optimization of moisture content of plant materials should be determined before exposure to liquid nitrogen to achieve high survival percentage rate [7].

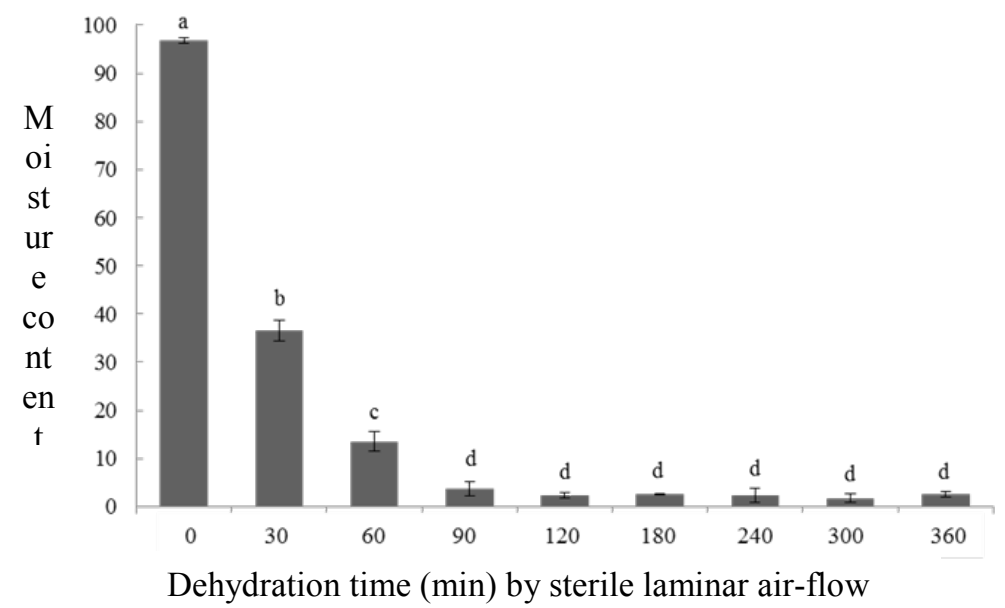

Figure 3 Moisture content is calculated by using wet basis equation with D cryo-plate technique

\section{Dehydration cryo-plate technique (D cryo-plate)}

The optimal dehydration time was determined by previous study. Due to the determination of moisture content, after 90 min of dehydration, it showed a steady status below $10 \%$ of moisture content. In the experiment, the dehydration period was covered by $0,30,60,90$, and 120 min to reduce water content from plant materials before cryopreservation. Germination percentage was observed after 4 weeks of culturing on modified VW agar medium (Table 1 and Figure 4). For non-cryopreserved seeds, no significant difference in germination percentage was observed after increasing the dehydration time (Figure 4). In the presence of high moisture content in plant materials at $0 \mathrm{~min}$ of dehydration, no germination of cryopreserved seeds was observed. High moisture content in the cells could cause the formation of intracellular ice nucleation, which causes cellular damage during freezing [5,47]. From the results, the decreasing moisture content was thus to increase the germination of seed cryopreservation. At 60 min of dehydration the highest germination was observed $(68.9 \%)$. However, after longer dehydration time to $120 \mathrm{~min}$, germination percentage of cryopreserved seeds decreased $(31.5 \%)$. The results indicated 
http://wjst.wu.ac.th

that higher and lower moisture content affected the germination percentage after cryopreservation. However, the development of seed to protocorm stage was referred to by the regrowth of $D$. cruentum Rchb. f. seed. It was observed after 12 weeks of culture. For non-cryopreserved seeds, the maximum regrowth percentage is $82.1 \%$, and the highest regrowth frequency of cryopreserved seeds was obtained after 60 min dehydration (57.8\%; Table 1). Due to the different dehydration time treatments, 60 min of dehydration time gave the highest germination and regrowth results for cryopreserved seeds, the same as Salma et al. [48] and Dhungana et al. [49], which reported high germination percentages of date palm proembryogenic and blueberry shoot observed after 60 min dehydration by using D cryo-plate technique.

Table 1 Effects of different dehydration times on germination and regrowth of non-cryopreserved (-LN) and cryopreserved $(+\mathrm{LN})$ seeds of Dendrobium cruentum Rchb. f. by D cryo-plate technique.

\begin{tabular}{ccccc}
\hline $\begin{array}{c}\text { Dehydration } \\
\text { time (min) }\end{array}$ & \multicolumn{2}{c}{ Germination percentage } & \multicolumn{2}{c}{ Regrowth percentage } \\
\cline { 2 - 5 } & $-\mathbf{L N}$ & $+\mathbf{L N}$ & $-\mathbf{L N}$ & $+\mathbf{L N}$ \\
\hline 0 & $89.3 \pm 2.62^{\mathrm{a}}$ & $0^{\mathrm{d}}$ & $82.1 \pm 3.25^{\mathrm{a}}$ & $0^{\mathrm{d}}$ \\
30 & $87.9 \pm 2.94^{\mathrm{a}}$ & $29.5 \pm 3.75^{\mathrm{c}}$ & $83.1 \pm 3.82^{\mathrm{a}}$ & $24.8 \pm 3.55^{\mathrm{c}}$ \\
60 & $88.9 \pm 2.81^{\mathrm{a}}$ & $68.9 \pm 4.91^{\mathrm{a}}$ & $77.8 \pm 3.71^{\mathrm{b}}$ & $57.8 \pm 5.24^{\mathrm{a}}$ \\
90 & $80.9 \pm 2.85^{\mathrm{a}}$ & $51.9 \pm 5.73^{\mathrm{b}}$ & $71.4 \pm 3.95^{\mathrm{bc}}$ & $42.9 \pm 5.68^{\mathrm{b}}$ \\
120 & $80.7 \pm 2.68^{\mathrm{a}}$ & $31.5 \pm 3.91^{\mathrm{c}}$ & $67.4 \pm 3.41^{\mathrm{c}}$ & $26.6 \pm 3.71^{\mathrm{c}}$ \\
\hline
\end{tabular}

*Mean value of germination seeds was evaluated within the same column. Same letters are not significantly different at $\mathrm{P} \leq 0.05 ; \mathrm{n}=20$ - 50 full seeds for each of ten replicates.
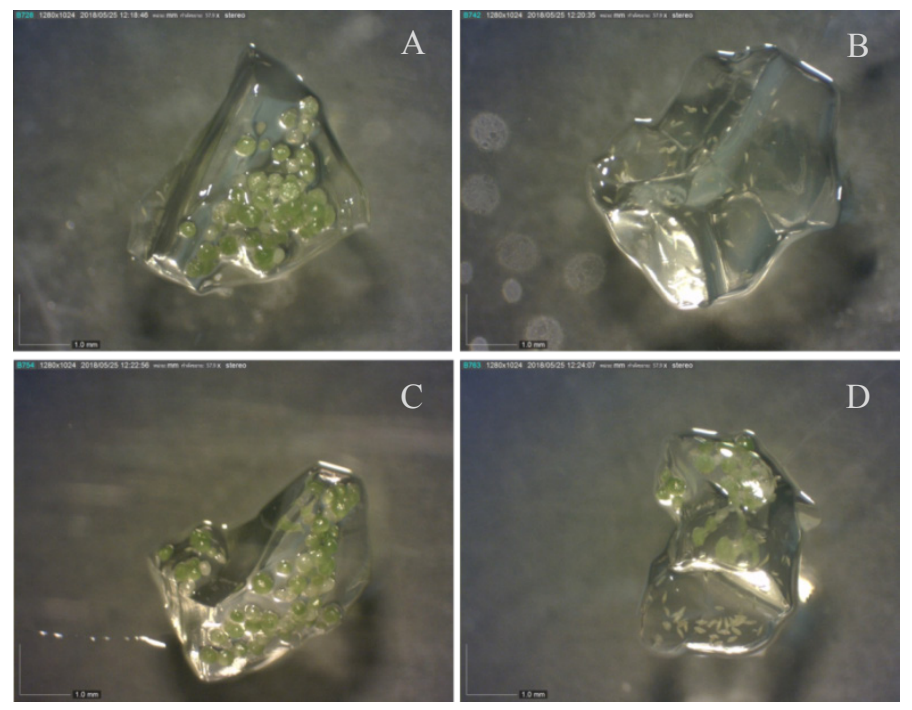

Figure 4 Germination of Dendrobium cruentum Rchb. f. seeds in response to laminar airflow dehydration and immersion into liquid nitrogen (LN) by D cryo-plate technique. A) D cryo-plate at 0 min without dehydration and without immersion in LN (-LN) (89.3\% seed germination), B) D cryo-plate with immersion into LN $(+\mathrm{LN})(0 \%$ seed germination), C) D cryo-plate at 60 min airflow dehydration without immersion into LN (-LN) (88.9\% seed germination), D) D cryo-plate at 60 min with airflow dehydration and immersion into LN (+LN) (68.9\% seed germination).

\section{Vitrification cryo-plate technique (V cryo-plate)}


http://wjst.wu.ac.th

The different exposure times of plant materials to PVS2 solution were designed to cover the interval of normal usage at $0,30,60,90$, and $120 \mathrm{~min}$. Germination percentages of $D$. cruentum Rchb.f. seeds were observed after 4 weeks in Table 2 and Figure 5. For non-cryopreserved seed germination percentages, they significantly decreased after $120 \mathrm{~min}$ of PVS2 treatment, from 90.7 to $77.9 \%$. For cryopreserved seeds, the highest germination percentages remained at 30 and 60 min of treatment (64.7 $65.2 \%)$. After longer treatment with PVS2 solution, germination percentages declined to $34.5 \%$ after 120 min of PVS2 treatment. Thammasiri [38] reported the successful germination of cryopreserved seeds of Dendrobium draconis (95\%), Dendrobium chrysotoxum (99\%), and Dendrobium hercoglossum (80 $\%$ ) using PVS2 solution at 30, 50, and $80 \mathrm{~min}$, respectively. However, the development of seed to protocorm stage was referred to by the regrowth of $D$. cruentum Rchb. f. seeds. It was observed after 12 weeks of culture. For non-cryopreserved seeds, the maximum regrowth percentage is $80.5 \%$. In addition, the highest regrowth frequency cryopreserved seeds $(57.8 \%)$ was obtained after 30 min of PVS2 exposure time treatment (Table 2).

From many reports, PVS2 solution has usually been applied to many plant species with various exposure times from 5 to $180 \mathrm{~min}$. However, the successful exposure time of PVS2 solutions to plant cryopreservation is around 20 to $60 \mathrm{~min}$ [50]. No longer exposure time has been used, because of their toxicity from DMSO and ethylene glycol, which are permeable cryoprotectants [51]. The effective PVS2 exposure time for D. cruentum Rchb. f. seed cryopreservation was $30 \mathrm{~min}$. Similarly, Rafique et al. [52] reported 30 min PVS2 treatment with V cryo-plate technique can maximize $100 \%$ of sugarcane shoot tip regeneration.

This is the first report on $D$. cruentum Rchb. f. seed cryopreservation by D cryo-plate and V cryoplate techniques. Both techniques can enhance the germination of D. cruentum Rchb. f. seeds after cryopreservation, two times higher than the previous study by vitrification method [38].

Table 2 Effect of different PVS2 exposure times on germination and regrowth of non-cryopreserved (LN) and cryopreserved (+LN) seeds of Dendrobium cruentum Rchb. f. by V cryo-plate technique.

\begin{tabular}{ccccc}
\hline Exposure time & \multicolumn{2}{c}{ Germination percentage } & \multicolumn{2}{c}{ Regrowth percentage } \\
\cline { 2 - 5 } to PVS2 (min) & $-\mathbf{L N}$ & $-\mathbf{L N}$ & $-\mathbf{L N}$ & $+\mathbf{L N}$ \\
\hline 0 & $90.7 \pm 2.69^{\mathrm{a}}$ & $0^{\mathrm{d}}$ & $80.5 \pm 3.66^{\mathrm{a}}$ & $0^{\mathrm{d}}$ \\
30 & $87.8 \pm 2.70^{\mathrm{a}}$ & $64.7 \pm 4.75^{\mathrm{a}}$ & $72.9 \pm 3.36^{\mathrm{a}}$ & $46.1 \pm 4.96^{\mathrm{a}}$ \\
60 & $86.4 \pm 3.29^{\mathrm{ab}}$ & $65.2 \pm 5.76^{\mathrm{a}}$ & $69.1 \pm 4.43^{\mathrm{ab}}$ & $39.1 \pm 5.92^{\mathrm{b}}$ \\
90 & $82.7 \pm 3.10^{\mathrm{ab}}$ & $46.6 \pm 5.35^{\mathrm{b}}$ & $69.3 \pm 3.78^{\mathrm{ab}}$ & $31.1 \pm 4.91^{\mathrm{bc}}$ \\
120 & $77.9 \pm 3.41^{\mathrm{b}}$ & $34.5 \pm 4.14^{\mathrm{c}}$ & $58.4 \pm 4.05^{\mathrm{b}}$ & $27.1 \pm 3.87^{\mathrm{c}}$ \\
\hline
\end{tabular}

*Mean value of germination seeds was evaluated within the same column. Same letters are not significantly different at $\mathrm{P} \leq 0.05 ; \mathrm{n}=20$ - 50 full seeds for each of ten replicates. 
http://wjst.wu.ac.th
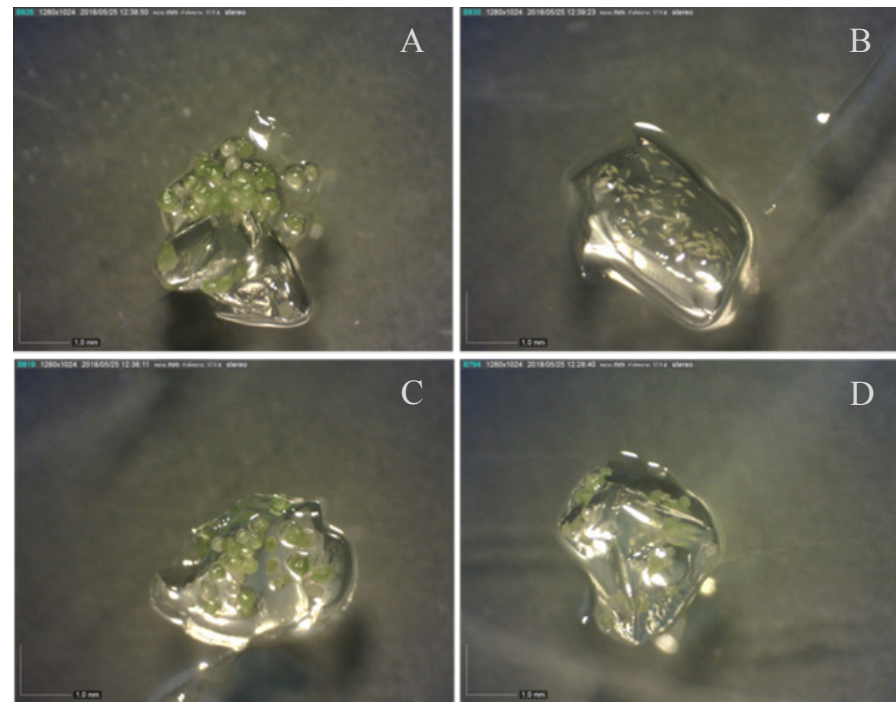

Figure 5 Germination of Dendrobium cruentum Rchb. f. seeds in response to PVS2 solution and immersion into liquid nitrogen (LN) by V cryo-plate. A) V cryo-plate at 0 min exposure time to PVS2 solution, and without immersion into LN (-LN) (90\% seed germination), B) V cryo-plate at 0 min exposure time to PVS2 solution with immersion into LN (+LN) $(0 \%$ of seed germination), C) V cryoplate technique at 30 min exposure time to PVS2 solution without immersion into LN (-LN) (87.8 \% seed germination), D) V cryo-plate at 30 min exposure time to PVS2 solution and immersion into LN (+LN) $(64.7 \%$ seed germination).

\section{Conclusions}

This study presents the successful cryopreservation protocol for D. cruentum Rchb. f. seeds with high germination and regeneration percentages by D cryo-plate and V cryo-plate technique. The effective technique for $D$. cruentum Rchb. f. seeds is D cryo-plate, with 60 min dehydration leading to $68.9 \%$ (germination) and $57.8 \%$ (regrowth). Moreover, it was clear that the suitable time for dehydration before immersion into liquid nitrogen plays a crucial role to ensure the survival of seeds after cryopreservation. These suitable cryopreservation conditions will benefit other explants of D. cruentum Rchb. f., such as protocorms, protocorm-like bodies, and shoot tips, to maintain their outstanding genotypes for long-term conservation.

\section{Acknowledgements}

We acknowledge financial support from the Science Achievement Scholarship of Thailand (SAST).

\section{References}

[1] F Engelman. In vitro Conservation Methods. In: CA Callow, BV Ford-Lloyd and HJ Newbury (Eds.). Biotechnology and Plant Genetic Resource. CAB International, Oxford, 1997, p. 119-61.

[2] E Popova, HH Kim, PK Saxena, F Engelmann and HW Pritchard. Frozen beauty: The cryobiotechnology of orchid diversity. Biotechnol. Adv. 2016; 34, 380-403.

[3] LE Towill. Vitrification as a Method to Cryopreserve Shoot Tips. In: RS Trigiano and DJ Gray (Eds.). Plant Tissue Concepts and Laboratory Exercises. CRC Press, Boca Raton, 1996, p. 297-304.

[4] F Engelmann and H Takagi. Cryopreservation of Tropical Plant Germplasm. IPGRI, Rome, Italy. 2000, p. 496.

[5] P Mazur. Freezing of living cells: Mechanisms and implications. Am. J. Physiol. 1984; 247, 125-42. 
http://wjst.wu.ac.th

[6] KK Kartha. Meristem Culture and Germplasm Preservation. In: KK Kartha (Ed.). Cryopreservation of Plant Cells and Organs. Boca Raton, Florida, 1985, p. 115-34.

[7] A Sakai. Cryopreservation of Germplasm of Woody Plants. In: YPS Bajaj (Ed.). Biotechnology in Agriculture and for Entry, v. 32, Cryopreservation of Plant Germplasm I, Springer Verlag, Berlin, Heierlberg, New York, 1995, p. 53-69.

[8] M Toribio and C Celestino. The use of biotechnology in the conservation of forest genetic resource. Inv. Agr. 2000; 2, 249-59.

[9] A Sakai, T Matsumoto, D Hirai and T Niino. Newly development encapsulation-dehydration protocol for plant cryopreservation. Cryo Lett. 2000; 21, 53-62.

[10] A Sakai and F Engelmann. Vitrification, encapsulation-vitrification and droplet-vitrification: A review. Cryo Lett. 2007; 28, 151-72.

[11] S Yamamoto, T Rafique, WS Priyantha, K Fukui, T Matsumoto and T Niino. Development of a cryopreservation procedure using aluminium cryo-plates. Cryo Lett. 2011; 32, 256-65.

[12] T Niino, S Yamamoto, K Fukui, CR Castillo Martínez, M Valle Arizaga, T Matsumoto and F Engelmann. Dehydration improves cryopreservation of mat rush (Juncus decipiens Nakai) basal stem buds on cryo-plates. Cryo Lett. 2013; 34, 549-60.

[13] F Engelmann. In vitro conservation of the cryopreservation of recalcitrant seed and vegetatively propagated species. Plant Genet. Resour. Newslett. 1997; 112, 9-18.

[14] TH Jang, SC Park, JH Yang, JY Kima, JH Seok, US Park, CW Choi, SR Lee and J Hanb. Cryopreservation and its clinical applications. Integr. Med. Res. 2017; 6, 12-8.

[15] A Sakai. Development of cryopreservation techniques. In cryopreservation of tropical plant germplasm: Current research progress and application. Tsukuba, Japan. 2000, p. 1-7.

[16] P Mohanty, MC Das, S Kumaria and P Tandon. High-efficiency cryopreservation of the medicinal orchid Dendrobium nobile Lindl. Plant Cell Tiss Org Cult. 2012; 109, 297-305.

[17] A Sakai, S Kobayashi and I Oiyama. Cryopreservation of nucellar cells of navel orange (Citrus sinensis Osb. Var. brasiliensis Tanaka) by vitrification. Plant Cell Rep. 1990; 9, 30-3.

[18] W Vendrame, RT Faria, M Sorace and SA Sahyun. Orchid cryopreservation. Cienc. Agrotec. 2014; 38, 213-29.

[19] J Fabre and J Dereuddre. Encapsulation-dehydration: A new approach to cryopreservation of Solanum shoot-tips. Cryo Lett. 1990; 11, 413-26.

[20] W Lurswijidjarus and K Thammasiri. Cryopreservation of shoot tip of Dendrobium Walter Oumae by encapsulation/dehydration. ScienceAsia 2004; 30, 293-9.

[21] T Niino, WK Wunna, K Watanabe, N Nohara, T Rafique, S Yamamoto, K Fukui, MV Arizaga, CRC Martinez, T Matsumoto and F Engelmann. Cryopreservation of mat rush lateral buds by air dehydration using aluminum cryo-plate. Plant Biotechnol. J. 2014; 31, 281-7.

[22] K Sekizawa, S Yamamoto, T Rafique, K Fukui and T Niino. Cryopreservation of in vitro-grown shoot tips of carnation (Dianthus caryophyllus L.) by vitrification method using aluminium cryoplates. Plant Biotechnol. J. 2011; 28, 401-5.

[23] S Yamamoto, K Fukui, T Rafique, NI Khan, CR Castillo Martinez, K Sekizawa, T Matsumoto and $\mathrm{T}$ Niino. Cryopreservation of in vitro-grown shoot tips of strawberry by the vitrification method using aluminium cryo-plates. Plant Genet. Resour. 2012a; 10, 14-9.

[24] S Yamamoto, T Rafique, K Fukui, K Sekizawa and T Niino. V-cryoplate procedure as an effective protocol for cryobanks: Case study of mint cryopreservation. Cryo Lett. 2012; 33, 12-23.

[25] S Yamamoto, RT Wunna, MV Arizaga, K Fukui, EJC Gutierrez, CRC Martinez, K Watanabe and T Niino. The aluminum cryo-plate increases efficiency of cryopreservation protocols for potato shoot tips. Am. J. Potato Res. 2015; 92, 250-7.

[26] T Matsumoto, K Yoshimatsu, N Kawahara, S Yamamoto and T Niino. Development of in vitro propagation by node culture and cryopreservation by v-cryo-plate method for Perilla Frutescens. Adv. Hortic. Sci. 2014; 28, 79-83.

[27] M Salma, L Fki, I Engelmann-Sylvestre, T Niino and F Engelmann. Comparison of dropletvitrification and D-cryoplate for cryopreservation of date palm (Phoenix dactylifera L.) polyembryonic masses. Sci. Hortic. 2014; 179, 91-7. 
http://wjst.wu.ac.th

[28] I Engelmann-Sylvestre and F Engelmann. Cryopreservation of in vitro grown shoot tips of Clinopodium odorum using aluminium cryoplates. In Vitro Cell Dev. Biol. Plant 2015; 51, 185-91.

[29] LDS Cordeiro, SG Claudia, N Albarello and F Engelmann. Cryopreservation of in vitro-grown shoot tips of Cleome rosea Vahl (Cleomaceae) using the V cryo-plate technique. In Vitro Cell Dev. Biol. Plant 2015; 51, 688-95.

[30] T Rafiquel, S Yamamoto, K Fukui, D Tanaka, MV Arizaga, M Abbas, T Matsumoto and T Niino. Cryopreservation of shoot-tips from different sugarcane varieties using cryo-plate technique. Pak. $J$. Agr. Sci. 2016; 53, 151-8.

[31] MV Arizaga, S Yamamoto, D Tanaka, K Fukai, N Nohara, T Nishikawa, K Watanabeand and T Niino, Cryopreservation of in vitro shoot tips of Ulluco (Ullucus tuberosus Cal.) using d cryo-plate method. Cryo Lett. 2017; 38, 419-27.

[32] RL Dressler. Phylogeny and Classification of the Orchid Family. Discorides Press, Portland, Oregon, 1993, p. 105-9.

[33] IJ Leitch, J Kahandawala, J Suda, L Hanson, MJ Ingrouille, MW Chase and MF Fay. Genome size diversity in orchids; consequences and evolution. Ann. Biol. 2009; 104, 469-81.

[34] G Seidenfaden. Orchid genera in Thailand XII, Dendrobium Sw. Botaniska Notiser. 1985; 83, 1295.

[35] B Lavarack, W Harries and G Stocker. Dendrobium and Its Relative. Timber Press, Portland. 2000.

[36] N Vaddhanaphuti. A Field Guide to the Wild Orchids of Thailand. $4^{\text {th }}$ ed. Silkworm Books, Thailand, 2005.

[37] K Kagawa. 2006, Cryopreservation of Dendrobium cruentum Rchb. f. M.S. Dissertation. Mahidol University, Bangkok, Thailand.

[38] K Thammasiri. Cryopreservation of some Thai orchid species. Acta Hortic. 2008; 788, 53-62.

[39] F Singh. Different staining of orchid seeds for viability testing. Am. Orchid Soc. Bull. 1981; 50, 416-8.

[40] NA Dowling and M Jusaitis. Asymbiotic in vitro germination and seed quality assessment of Australian terrestrial orchids. Aust. J. Bot. 2012; 60, 592-601.

[41] G Volk and C Walters. Plant vitrification solution 2 lowers water content and alters freezing behavior in shoot tips during cryoprotection. Cryobiology 2006; 52, 48-61.

[42] T Matsumoto, A Saki and Y Nako. A novel preculturing for enhancing the survival of in vitrogrown meristems of wasabi (Wasabia japonica) cooled to $-196^{\circ} \mathrm{C}$ by vitrification. Cryo Lett. 1998 ; 19, 27-36.

[43] M Suzuki, M Ishikawa and T Akihama. A novel preculture method for the induction of desiccation tolerance in gentian axillary buds for cryopreservation. Plant Sci. 1998; 135, 69-76.

[44] MT Gonzalez-Arnao, F Engelmann, C Urra, M Morenza and A Rios. Cryopreservation of Citrus apices using the encapsulation-dehydration technique. Cryo Lett. 2000; 19, 177-82.

[45] MDA Padro, A Frattarelli, A Sgueglia, E Condello, C Damiano and E Caboni. Cryopreservation of white mulberry (Morus alba L.) by encapsulation-dehydration and vitrification. Plant Cell Tiss Organ Cult. 2012; 108, 167-72.

[46] N Jitsopakul, K Thammasiri and K Ishikawa. Cryopreservation of Vanda coerulea protocorms by encapsulation-dehydration method. In: Proceedings of the $33^{\text {rd }}$ Congress on Science and Technology of Thailand, Thailand, 2007.

[47] DJ Wesley-Smith, P Berjak, NW Pammenter and C Walters. Intracellular ice and cell survival in cryo-exposed embryonic axes of recalcitrant seeds of Acer saccharinum: An ultrastructural study of factors affecting cell and ice structures. Ann. Bot. 2014; 113, 695-709.

[48] M Salma, L Fki, I Engelmann-Sylvestre, T Niino and F Engelmann. Comparison of dropletvitrification and D-cryoplate for cryopreservation of date palm (Phoenix dactylifera L.) polyembryonic masses. Sci. Hortic. 2014; 179, 91-7.

[49] SA Dhungana, H Kunitake, T Niino, S Yamamoto S, K Fukai, D Tanaka, S Maki and T Matsumoto. Cryopreservation of blueberry shoot tips derived from in vitro and current shoots after cryopreservation using D cryo-plate technique. Plant Biotech. 2017; 34, 1-5. 
http://wjst.wu.ac.th

[50] D Kulus and M Zalewska. Cryopreservation as a tool used in long-term storage of ornamental species-A review. Sci. Hortic. 2014; 168, 88-107.

[51] LC Silva, SG Claudia, N Albarello and F Engelmann. Cryopreservation of in vitro-grown shoot tips of Cleome rosea Vahl (Cleomaceae) using the V cryo-plate technique. In Vitro Cell. Dev. Biol. 2015; 51, 688-95.

[52] T Rafique, S Yamamoto, K Fukai, Z Mahmood and T Niino. Cryopreservation of sugarcane using the V cryo-plate technique. Cryo Lett. 2015; 36, 51-9. 